\title{
Proliferative lymphocyte responses to virus antigens homologous to GAD65 in IDDM
}

\author{
D. B. Jones, I. Crosby \\ Department of Immunology, The University of Liverpool, Liverpool, UK
}

\begin{abstract}
Summary Virus infection has been proposed as an initiating factor in the aetiology of insulin-dependent diabetes mellitus (IDDM). We have examined lymphocyte proliferation to virus proteins which demonstrate sequence similarity to the beta-cell autoantigen glutamic acid decarboxylase (GAD)65. The magnitude and frequency of response to coxsackie B viruses and adenovirus in a T-cell proliferation assay was significantly higher in a group of recently diagnosed IDDM subjects than in non-diabetic control subjects. The frequency of positive response to the coxsackie B viruses was also significantly higher in IDDM subjects expressing the DRB $1 * 04$ major histocompatibility complex (MHC) haplotype than the DRB 1*03 haplotype. There was no evidence that
\end{abstract}

non-aspartate residue at position 57 of DQB 1 genes influenced virus responses in the IDDM group. The coxsackie homology was in amino acids 258-266 and the adenovirus homology was in amino acids 509524 of GAD65. Both these regions are suspected to be T-cell epitopes in IDDM. These results indicate a disease and MHC class II association between coxsackie B virus infection and IDDM and an association between adenovirus infection and IDDM. [Diabetologia (1996) 39: 1318-1324]

Keywords Lymphocyte, glutamic acid decarboxylase (GAD65), insulin dependent diabetes mellitus, viruses, major histocompatibility complex (MHC), coxsackie, adenovirus.
Insulin-dependent diabetes mellitus (IDDM) is the result of the autoimmune destruction of the pancreatic islet beta cells [1]. The disease is characterised histologically by a lymphocytic infiltrate of the islets, insulitis, and immunologically by the presence of beta-cell reactive autoantibodies and $\mathrm{CD}^{+} \mathrm{T}$ cells. Several genetic loci have been identified that may influence the susceptibility to IDDM, most importantly the DRB and DQB genes in the major histocompatibility complex (MHC) on the short arm of

Received: 1 February 1996 and in revised form: 6 May 1996

Corresponding author: Dr. D. B.Jones, Wirral Hospital, Arrowe Park, Arrowe Park Road, Upton, Wirral, Merseyside L49 5PE, UK

Abbreviations: IDDM, Insulin-dependent diabetes mellitus; MHC, major histocompatibility complex; GAD, glutamic acid decarboxylase; NOD, non-obese diabetic; PCR, polymerase chain reaction; MANOVA, multivariate analysis of variance; aa, amino acids. chromosome 6 [2], with $95 \%$ of subjects with IDDM expressing the DRBI*03 and/or DRBI*04 MHC haplotypes. However, studies of IDDM concordance in genetically identical monozygotic twins show that only about one-third of the siblings of the affected proband also have IDDM [3]. Thus, it seems likely that an environmental factor is essential in converting genetic susceptibility into beta-cell loss and IDDM.

Several viruses have been associated with the development of IDDM through individual case reports including mumps [4] and coxsackie B viruses [5]. The high incidence of IDDM in subjects with congenital rubella syndrome has also been recognised [6]. While a diabetogenic coxsackie $\mathrm{B}$ virus was recovered from the pancreas of one individual who died of diabetic ketoacidosis soon after diagnosis [7], more recent investigation of several similar pancreata failed to identify any viral genome, suggesting that in most cases continuous infection of the beta cells does not occur [8]. 
Activation of a T-cell population against an environmental antigen may lead to the development of autoimmune disease if the epitope recognised shows sequence similarity with a self protein, a hypothesis referred to as molecular mimicry. Several studies have investigated molecular mimicry in IDDM. Karjalainen et al. [9] and Miyazaki et al. [10] found evidence for antibody and T-cell cross reactivity between bovine serum albumin and an islet cell protein, p69/ICA69, although other workers have disputed these findings [11]. Antibody cross reactivity between a rubella virus antigen and an unknown islet cell protein has also been reported [12].

Most interest has focussed on a sequence homology between the $65 \mathrm{kDa}$ beta-cell antigen glutamic acid decarboxylase (GAD)65 and the coxsackie B virus $\mathrm{P} 2-\mathrm{C}$ protein, which shares an exact six amino acid match, (PEVKEK) [13], and several conserved substitutions. GAD65 is an important beta-cell autoantigen in IDDM. Cellular [14] and humoral [13] autoreactivity against GAD65 precedes disease onset in humans, and GAD65 is among the earliest targets of the autoimmune response in an animal model of diabetes, the non-obese diabetic (NOD) mouse [15].

If T-cell reactivity to the PEVKEK region is of pathological significance in human IDDM, then it is clearly important to determine whether activation of this T-cell population is the result of coxsackie B virus infection. Several studies have attempted to investigate the frequency of coxsackie B infection in IDDM, usually by measuring titres of virus-specific antibody in the sera of newly diagnosed IDDM subjects [16]. While the majority indicate that virus-specific titres are increased [17, 18], Atkinson et al. [19] were unable to find significantly raised titres of coxsackie B specific antibody in subjects who demonstrated positive proliferative responses to the GAD65 and P2-C peptides.

However, IDDM has a long prodromal period: the first evidence of autoimmunity, islet cell antibodies, are detected in many cases several years before the onset of clinical disease [20]. We have adopted the Tcell proliferation assay to detect virus antigen-specific $T$ cells. If a virus is responsible for initiation of a latent GAD65 reactive T-cell population, it is possible that a T-cell response against this agent will be observed even when serum antibody titres have become undetectable.

\section{Patients and methods}

Subject groups. Twenty-six newly diagnosed IDDM subjects were recruited from patients attending diabetes clinics at Arrowe Park Hospital, Wirral, UK. Twenty-four age- and sex-matched control subjects were selected from members of laboratory staff. Mean age of IDDM subjects was 18.6 years \pm 3.7 years and 21.0 years \pm 4.6 years for control subjects. All IDDM subjects were studied within 3 months of diagnosis.
Database searches. The amino acid sequence of GAD65 was used as a probe sequence of the OWL composite protein sequenced database using the FASTA program of the GCG suite. Secondary searches were performed using the GAD65 sequences that corresponded to the primary and secondary epitopes of GAD65 in the NOD mouse, from the human IDDM specific immunodominant region identified by Lohmann et al. [21], and the PEVKEK based sequence from studies of human IDDM. In each case, standard comparison matrices were used, and the first 500 sequences were examined for sequence similarities with virus proteins.

Selection of virus antigens. Protein preparations from 11 of the viruses identified in the database search were available for study in proliferation assays in the form of lysates from virus-infected cell lines (Virion Products). Most of these viruses had not been previously associated with IDDM. Two other viruses were included as control antigens for the proliferation assay. Mumps virus was included in the study as a virus which had been associated with IDDM in individual case reports, but with no identified sequence homology to GAD65. Arenavirus was included as a further control antigen, which exhibited no sequence homology and had not been associated with IDDM. Uninfected cell lines were used to determine the level of virus-specific proliferation (mean response with virus infected cell line-mean response with uninfected cell line). Arenavirus, herpes simplex, mumps, polio, adenovirus and coxsackie viruses were cultivated in vero cells, cytomegalo virus and varicella zoster in Hel fibroblasts and rotavirus in rita cells.

T-cell proliferation assays. Peripheral blood lymphocytes were prepared by Ficoll density gradient centrifugation from $30 \mathrm{ml}$ of venous blood. T-cell proliferation assays were performed according to the method of Atkinson et al. [14] with six replicates per antigen in 96-well microtitre plates, with $1 \times 10^{5}$ peripheral blood lymphocytes per well, together with the concentration of each antigen that stimulated the greatest response in titration experiments (data not shown), in RPMI-1640 medium (Gibco), supplemented with $10 \%$ heat-inactivated human $\mathrm{AB}$ serum. The cells were incubated for 6 days at $37^{\circ} \mathrm{C}, 5 \% \mathrm{CO}_{2}$, pulsed for $6 \mathrm{~h}$ with $1 \mu \mathrm{Ci}^{3} \mathrm{H}$-Thymidine (Amersham), then harvested semiautomatically onto glass fibre mats (Titertek). Incorporation of ${ }^{3} \mathrm{H}$-Thymidine was assessed by liquid scintillation counting (LKB 1215; Rackbeta). Mean proliferative responses for each antigen were determined. The virus specific stimulation index was calculated using the formula stimulation index $=$ mean virus specific proliferation - mean background proliferation. As in other studies a stimulation index greater than 3 was considered positive: this threshold represented the mean proliferative response of unstimulated wells plus 3 standard deviations.

MHC class II genotyping. Class II MHC genotyping and determination of the absence of aspartate at position 57 of DQB genes utilised the polymerase chain reaction (PCR) with allele specific oligonucleotide primers, using standard conditions, according to the method of Olerup and Zetterquist [22]. Individuals were distributed into one of four classes; DRB1 *03/X, DRB1 $* 04 / \mathrm{X}, \mathrm{DRB} 1 * 03 / \mathrm{DRB} 1 * 04$, or $\mathrm{X} / \mathrm{X}$, where $\mathrm{X}$ indicates a class II MHC haplotype which is neither DRB1*03 nor DRB1*04.

\section{Statistical analysis}

Multivariate analysis of variance (MANOVA) was used to determine whether there was an overall significant difference in virus response between the groups. To investigate whether 
Table 1. Sequence homologies between GAD65 and virus proteins

\begin{tabular}{|c|c|c|c|}
\hline \multicolumn{2}{|l|}{ GAD65 region 1} & \multirow{2}{*}{$\frac{\text { Amino acids }}{509-524}$} & \multirow{2}{*}{$\begin{array}{l}\text { Sequence } \\
\text { V P P S L R T LE D N E ER M S }\end{array}$} \\
\hline GAD65 & & & \\
\hline Virus & Protein & Amino acids & Sequence \\
\hline $\begin{array}{l}\text { Adenovirus } \\
\text { Type } 42\end{array}$ & E1A & $104-119$ & $L \mathbf{P} \mathbf{P} \mathbf{S} S E$ A $D E A \mathbf{E} \mathbf{E} \mathrm{R} \mathrm{E}$ \\
\hline $\begin{array}{l}\text { Cytomegalovirus } \\
\text { AD169 }\end{array}$ & HWLF & $74-89$ & $\mathrm{D} \mathbf{P} \mathbf{P} A \mathbf{L} \mathbf{R} \mathbf{T} \mathrm{Y} Q R H Q \mathrm{G} \mathrm{T} \mathrm{T}$ \\
\hline Epstein-Barr virus B95-8 & UL2 & $11-126$ & V P P S L R $N I Y A E \mathrm{~L} H \mathbf{R} \mathrm{S} \mathrm{L}$ \\
\hline Herpes simplex virus & UL55 & $92-107$ & H P P V L R $E \mathbf{L} \mathbf{E} D K \mathrm{R} G \mathrm{~V} \mathrm{R} \mathrm{L}$ \\
\hline GAD65 & & $258-266$ & MF P E V K E K G \\
\hline Virus & Protein & Amino acids & Sequence \\
\hline $\begin{array}{l}\text { Coxsackie B1 } \\
\text { virus }\end{array}$ & $\mathrm{P} 2-\mathrm{C}$ & $36-44$ & I L P E V K E K H \\
\hline $\begin{array}{l}\text { Coxsackie B1 } \\
\text { virus }\end{array}$ & $\mathrm{P} 2-\mathrm{C}$ & $36-44$ & I L P E V K E K H \\
\hline $\begin{array}{l}\text { Varicella-zoster } \\
\text { virus }\end{array}$ & transport protein & $617-625$ & $\mathrm{~L} \mathbf{F} P H L \mathbf{K} \mathbf{E} E \mathrm{~L}$ \\
\hline
\end{tabular}

Letters in bold face, amino acid homology; letters in italic, conserved substitution

responses to specific viruses were significantly different in the IDDM and non-diabetic subjects, and to assess interactions between specific virus response and class II MHC expression, the univariate statistics were examined. Stimulation indices were transformed to normalise the data for analysis by MANOVA.

Differences in stimulation index between IDDM and nondiabetic control groups were also assessed using Mann-Whitney U-tests, and differences in frequencies of positive response were determined with chi square tests, using two-tailed Fisher's exact tests when frequencies in a subgroup were below five. In Mann-Whitney, chi square, and Fisher's exact tests, $p$-values less than 0.0039 were considered sufficiently significant to take account of multiple tests.

\section{Results}

The initial database search using the entire GAD65 sequence revealed several sequence homologies with virus proteins (GAD65 amino acids(aa)159-191, adenovirus E3.9 kDa glycoprotein aa2-35; GAD65 aa260-265, coxsackie B viruses $\mathrm{P} 2-\mathrm{C}$ protein aa3743; GAD65 aa385-407, cytomegalovirus UL 132 protein aa242-264; GAD65 aa538-551, herpes simplex virus 372-386; GAD65 aa265-278, polio virus genome polyprotein aa1901-1914; GAD65 aa108-137, rotavirus VP7 protein aa10-37; GAD65 aa 165-176, tick-borne encephalitis virus genome polyprotein aa557-568; GAD65 aa17-38, varicella-zoster virus $74 \mathrm{kDa}$ trans-inducing protein aa 29-49). With the exception of the coxsackie B virus similarity, no homology was found in regions of GAD65 that were identified as containing or representing T-cell epitopes [23].

However, secondary searches focussing on two peptides of GAD65 that may represent T-cell epitopes revealed that the same viruses often exhibited other sequence homologies in these regions. The first comprised the primary epitope of GAD65 in the NOD mouse and was part of the region that is immunodominant in one study of human IDDM [21]. Six virus protein homologies were identified in this region. The second sequence represents the secondary epitope of GAD65 in the NOD mouse, has been shown to stimulate T-cell responses in some human IDDM subjects $[19,24]$ and exhibits sequence similarity with the P2-C protein of several coxsackie B viruses [13]. Three virus homologies were identified in this region. The virus homologies with GAD65 in these regions are shown in Table 1.

The frequencies of positive responses for the virus antigens used in the T-cell proliferation assay and statistical data are illustrated in Table 2. The multivariate analysis showed that there was no significant difference in overall virus response between the IDDM and control group $(F=1.50, p=0.175)$, indicating that there was no general excess T-cell proliferation in the IDDM group. Significant differences were 
Table 2. Frequencies of positive response to antigens

\begin{tabular}{|c|c|c|c|c|c|}
\hline \multirow[t]{2}{*}{ Virus } & \multicolumn{2}{|c|}{ Positive response frequencies } & \multicolumn{3}{|c|}{ Statistical significance } \\
\hline & IDDM & Control & MANOVA & $\begin{array}{l}\text { p-value } \\
\left(\chi^{2} / \text { Fisher's exact test }\right)\end{array}$ & $\begin{array}{l}\text { p-value } \\
\text { (Mann-Whitney U-test) }\end{array}$ \\
\hline CoxB1 & $11 / 26$ & $4 / 24$ & 0.003 & NS & 0.0001 \\
\hline CoxB4 & $14 / 26$ & $6 / 24$ & 0.011 & NS & 0.0035 \\
\hline CoxB6 & $15 / 26$ & $5 / 24$ & 0.031 & NS & 0.0014 \\
\hline Pooled Cox & $18 / 26$ & $6 / 24$ & NA & 0.002 & NS \\
\hline CMV & $6 / 26$ & $0 / 24$ & NS & NS & NS \\
\hline EBV & $7 / 26$ & $1 / 14$ & NS & NS & NS \\
\hline HSV & $20 / 26$ & $10 / 24$ & NS & NS & NS \\
\hline Mumps & $13 / 26$ & $8 / 24$ & NS & NS & NS \\
\hline Polio & $6 / 26$ & $1 / 24$ & 0.015 & NS & 0.0001 \\
\hline Rota & $6 / 26$ & $4 / 24$ & NS & NS & NS \\
\hline TBEV & $8 / 26$ & $6 / 24$ & NS & NS & NS \\
\hline
\end{tabular}

NA, not applicable

observed with the polio virus, adenovirus, and the coxsackie $B$ virus preparations in the MANOVA univariate $F$-tests and Mann-Whitney U-test (Table 2 ). A stimulation index greater than 3 against any one of the three coxsackie $\mathrm{B}$ virus antigens generated a positive response in the pooled coxsackie B virus entry in Table 2 . This entry was used to estimate the number of subjects who showed evidence of coxsackie B infection (18/26 IDDM, 6/24 control subjects). Significant differences in frequencies of positive response were only obtained for the adenovirus and pooled coxsackie B viruses (Table 2), indicating that the significant differences in the magnitude of response for the polio virus reflected difference in $\mathrm{T}$ cell proliferation in non-responding individuals. No significant differences in frequency or magnitude of response were observed with the arenavirus, cytomegalovirus, Epstein-Barr virus, herpes simplex virus, mumps virus, rotavirus, tick borne encephalitis virus, or varicella-zoster virus antigens. Stimulation indices for each of the virus antigens are illustrated in Figures 1 and 2.

The incidence data was also used to analyse class II MHC associations with virus responses. The subject groups were divided into the four subgroups based on MHC haplotype, DRB1*03/DRB1*04 heterozygotes (8/26 IDDM, 0/24 control subjects), DRB $1 * 03 /$ $\mathrm{X}$ (8/26 IDDM, 8/24 control subjects), DRB1*04/X (10/26 IDDM, 7/24 control subjects), and X/X (0/26 IDDM, 9/24 control subjects). The association between incidence of virus response and $\mathrm{MHC}$ haplotype was determined using the DRB $1 * 03 / \mathrm{X}$ and DRB $1 * 04 / \mathrm{X}$ subgroups. The incidence of positive responses to each antigen is shown in Table 3 . The frequency of response to coxsackie B viruses was significantly higher in IDDM subjects with DRB $1 * 04 / \mathrm{X}$ than $\mathrm{DRB} 1 * 03 / \mathrm{X}(p<0.05)$. In addition, the frequency of positive response in the DRB $1 * 04 / \mathrm{X}$ group
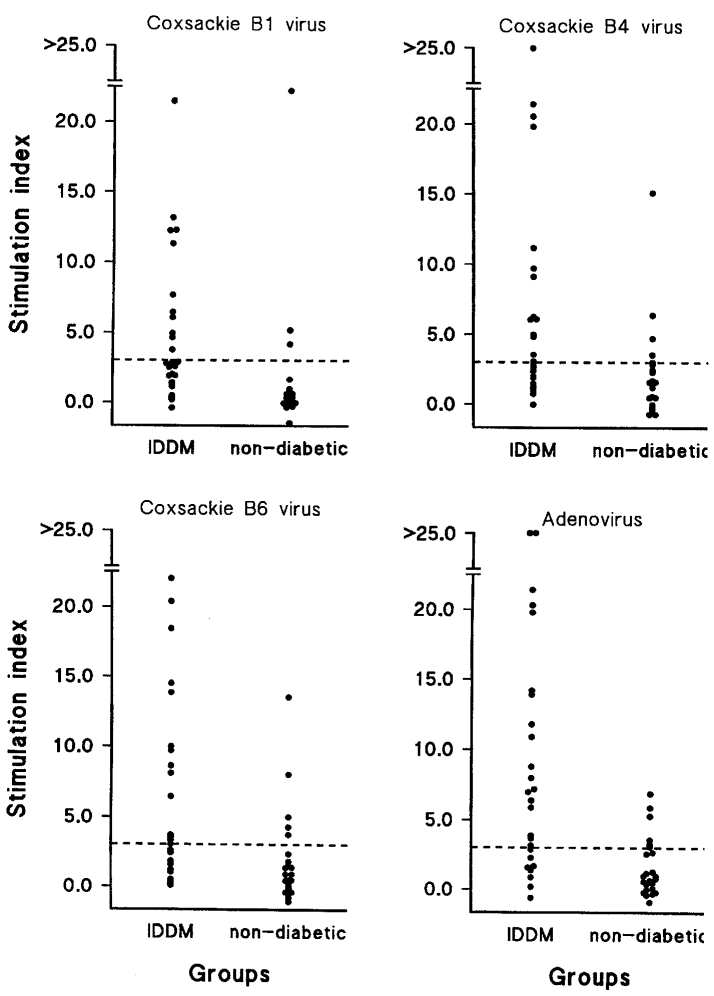

Fig. 1. Coxsackie B virus and adenovirus stimulation indices

was significantly higher in the IDDM subjects than the non-diabetic control subjects $(p<0.005)$. Conversely, the frequency of positive response to coxsackie $B$ viruses did not differ significantly between DRB1*03/X and DRB1*04/X individuals in the nondiabetic control group, and there was no significant difference between DRB1*03/X individuals in the IDDM and control group. The univariate $F$-tests indicated that the T-cell response to the coxsackie B1 virus $(F=4.99, p=0.031)$, but no other antigen, was dependent on disease group and class II MHC 
Table 3. MHC class II restriction of coxsackie B virus and adenovirus response

\begin{tabular}{lllll}
\hline Coxsackie B virus & $\mathrm{X} / \mathrm{X}$ & $\mathrm{DRB} 1 * 03 / \mathrm{DRB} 1 * 04$ & $\mathrm{DRB} 1 * 03 / \mathrm{X}$ & $\mathrm{DRB} 1 * 04 / \mathrm{X}$ \\
IDDM subjects & - & $6 / 8$ & $3 / 8$ & $9 / 10$ \\
Non-diabetic control subjects & $2 / 9$ & - & $\mathrm{DRB} 1 * 03 / \mathrm{X}$ & $1 / 7$ \\
Adenovirus & $\mathrm{X} / \mathrm{X}$ & $\mathrm{DRB} 1 * 03 / \mathrm{DRB} 1 * 04$ & $3 / 8$ & $\mathrm{DRB} 1 * 04 / \mathrm{X}$ \\
IDDM subjects & - & $6 / 8$ & $3 / 8$ & $7 / 10$ \\
Non-diabetic control subjects & $4 / 9$ & - & $0 / 7$ \\
\hline
\end{tabular}
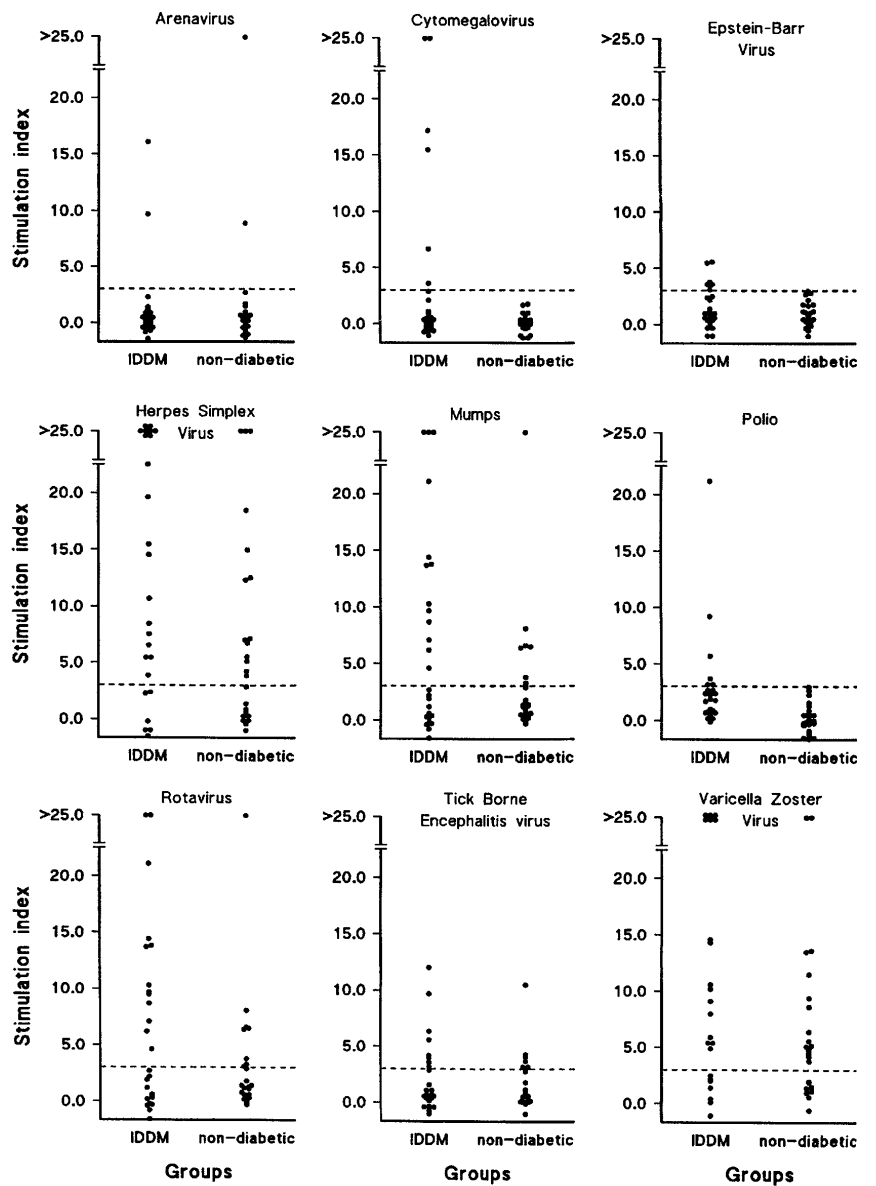

Fig. 2. Virus stimulation indices

haplotype. For the adenovirus antigen, there was no significant difference in the frequency of positive response between DRB $1 * 03 / \mathrm{X}$ and DRB $1 * 04 / \mathrm{X}$ individuals in the IDDM group, or between the IDDM and non-diabetic DRB1*03/X subgroups. The frequency of positive response was significantly higher in IDDM subjects with DRB1*04/X than the DRB1*04/X non-diabetic control group $(p<0.01)$. This analysis was repeated dividing the IDDM group on the basis of the absence of aspartate at position 57 of DQB 1 genes. No significant association was identified with any virus antigen (data not shown).

\section{Discussion}

In this paper, we have shown that the magnitude of Tcell response and frequency of positive T-cell proliferative responses to coxsackie $\mathrm{B}$ viruses and adenovirus are significantly higher in IDDM subjects than non-diabetic control subjects. Coxsackie B viruses have been considered to be of aetiological importance in IDDM for many years. Estimates of the incidence of coxsackie B infection derived from serological studies suggested that $46 \%$ of newly diagnosed IDDM subjects have significant antibody titres [18]. An association between higher titres of coxsackie B virus antibody and expression of the DRB $1 * 03$ MHC haplotype has been identified [25], in contrast to our data, confirming an earlier study [26] that Tcell responses are associated with the DRB1*04 haplotype. The use of serological studies to assess the incidence of coxsackie B virus infection in IDDM may have underestimated the true frequency of infection, as in our study, the use of the T-cell proliferation assay revealed a higher incidence of coxsackie B virus responses, with $69 \%$ of IDDM subjects exhibiting positive T-cell responses to at least one coxsackie B virus antigen. It is possible that this may reflect the presence of a significant population of PEVKEK responsive $\mathrm{T}$ cells that cross-react with the $\mathrm{P} 2-\mathrm{C}$ protein from the coxsackie $\mathrm{B}$ antigen, without reflecting prior coxsackie B virus infection. However, some of the subjects in the study gave positive T-cell responses to only one or two of the three antigens used, while other subjects with positive responses to all three coxsackie antigens, showed significant differences in stimulation index between the three protein preparations (data not shown), which may reflect the presence of additional type-specific T-cell responses, implying that coxsackie $\mathrm{B}$ virus infection was responsible for the activation of the T-cell population.

A number of recent studies have investigated antibody cross reactivity in the PEVKEK region [27, 28]. It is generally agreed that autoantibodies, while of diagnostic interest, are of limited pathological significance in IDDM. Studies of T-cell reactivity to the PEVKEK region in the NOD mouse suggest that the PEVKEK region appears to constitute a secondary T-cell epitope [29], and that T-cell cross reactivity does occur between the GAD65 and P2-C derived sequences, even using whole proteins [30]. 
In human IDDM, T-cell responses against the GAD65 derived PEVKEK peptide and the P2-C peptide have been reported [19,24], but are weaker than those found in the NOD mouse, and are found in only a few subjects with IDDM. One comprehensive investigation of GAD65 epitopes in IDDM showed that the immunodominant region encompassed the primary epitope from the NOD mouse, but did not suggest the PEVKEK region contained an epitope, although the use of pooled peptides in this study may have masked T-cell responses [21].

The higher frequency of positive response in this study compared to serological studies may indicate that coxsackie B virus infection is involved in the initiation of the autoimmune attack on the islet beta cells, and that the responses observed reflect the presence of peripheral memory $\mathrm{T}$ cells. The antigen preparations used in this study were lysates from infected cell lines with no infected cell line preparations as controls. It is possible that other antigens may have been induced in the viral cell lines which were not present in control preparations. Alternatively, the possibility of chronic coxsackie B infection has been proposed.

The evidence of MHC restriction in the T-cell response to coxsackie B viruses is of particular interest. An affinity between the PEVKEK epitope and DQB1*0302(DQw8) has been noted [30]. In our study, all of the subjects with DQB1*0302 also expressed the DRB1*04, so it was not possible to determine whether the MHC restriction observed with coxsackie B viruses was more strongly associated with the DR or DQ locus. Nonetheless, the significant difference in frequency of response between DRB $1 * 03 / X$ and DRB1 $* 04 / X$ individuals in the IDDM group is indicative of an antigen specific phenomena, and strengthens the view that the PEVKEK epitope of GAD65 may be of significant aetiological importance, and a possible target of therapy, at least in IDDM subjects expressing the DRB1*04 MHC haplotype.

In contrast, the results obtained with the adenovirus antigen were unexpected. There have been no reports indicating that adenovirus infection is a significant event in the aetiology of IDDM. In our study, the frequency of positive response was not significantly higher in the DRB1*03/X than DRB1*04/X IDDM subjects. An examination of the sequence similarity between the adenovirus E1A and IIIA proteins and GAD65 shows that there is a strong homology within the region that was identified as a GAD65 Tcell epitope in the NOD mouse [29], and is also within the region of GAD65 that Lohmann et al. [21] showed to be immunodominant in human IDDM.

A recent report of T-cell reactivity to autoantigens in multiple sclerosis may be of importance for future studies of GAD65 in IDDM. Responses from myelin basic protein specific T-cell clones to peptides from environmental agents has shown that molecular mimicry occurs between peptides that exhibit only limited overall sequence similarity, but with conserved motifs in critical amino acids that defined MHC binding and T-cell recognition [31]. In this paper, the amino acids that specified MHC affinity and T-cell activation of the T-cell clones were identified by comprehensive substitution of the myelin basic protein epitope. In the case of human IDDM, GAD65 T-cell epitopes have yet to be conclusively identified, and our study has used a less sensitive database search based on overall sequence similarity. We have noted several sequence homologies between GAD65 and virus proteins in two regions of GAD65 that may contain T-cell epitopes, but found IDDM associated T-cell responses with only two virus antigens. The development and characterisation of GAD65 T-cell clones is clearly a significant goal of IDDM research.

However, further investigation of both coxsackie B viruses and adenoviruses in IDDM is also clearly important. It is possible that in at-risk subjects, immunisation against the infectious agents, perhaps using modified vaccines that do not prime against the putative cross-reactive domains, may prevent the activation of the autoimmune response against the pancreatic islet beta cells.

Acknowledgements. We are grateful to Dr. R. Barnes for helpful advice, to Dr. A. Coulson for performing the primary sequence searches, and to Dynal for the supply of Asp57 typing kits. The sequence analysis used the SEQNET facilities at Daresbury laboratories. Technical asistance was provided by Mr. N. Armstrong. We are indebted to the Mersey Regional Health Authority, British Diabetic Association and to Wirral Diabetic Children's group, for their support.

\section{References}

1. Atkinson MA, MacLaren NK (1994) The pathogenesis of insulin-dependent diabetes mellitus. New Engl J Med 331: 1428-1436

2. Davies JL, Kawaguchi Y, Bennett ST et al. (1994) A genome-wide search for human type-I diabetes susceptibility genes. Nature 371: 130-136

3. Kaprio J, Tuomilehto J, Koskenvuo M et al. (1992) Concordance for type 1 (insulin-dependent) diabetes mellitus in a population-based cohort of twins in Finland. Diabetologia 35: $1060-1067$

4. Harris HF (1899) A case of diabetes mellitus quickly following mumps. Boston Med Surg J 140: 465-469

5. Szopa TM, Titchener PA, Portwood ND, Taylor KW (1993) Diabetes mellitus due to viruses - some recent developments. Diabetologia 36: 687-695

6. Menser MA, Forrest JM, Bransby RD (1978) Rubella infection and diabetes mellitus. Lancet I: 57-60

7. Yoon J-W, Austin M, Onodera T, Notkins AL (1979) Virusinduced diabetes mellitus. Isolation of a virus from a child with diabetic ketoacidosis. New Engl J Med 300: 1173-1178

8. Buesagomez J, Delatorre JC, Dyrberg T et al. (1994) Failure to detect genomic viral sequences in pancreatic tissues 
from two children with acute-onset diabetes mellitus. J Med Virol 42: 193-197

9. Karjalainen J, Martin JM, Knip M et al. (1992) A bovine albumin peptide as a possible trigger of insulin-dependent diabetes mellitus. N Engl J Med 327: 302-307

10. Miyazaki I, Cheung RK, Gaedigk R et al. (1995) T cell activation and anergy to islet cell antigen in type I diabetes. J Immunol 154: 1461-1469

11. Atkinson MA, Bowman MA, Kao KJ et al. (1993) Lack of immune responsiveness to bovine serum albumin in insulin-dependent diabetes. N Engl J Med 329: 1853-1858

12. Karounos DG, Wolinsky IS, Thomas JW (1993) Monoclonal antibody to rubella virus capsid protein recognizes a beta-cell antigen. J Immunol 150: 3080-3085

13. Kaufman DL, Erlander MG, Clare SM et al. (1992) Autoimmunity to two forms of glutamate decarboxylase in insulin-dependent diabetes mellitus. J Clin Invest 89: 283-292

14. Atkinson MA, Kaufman DL, Campbell L et al. (1992) Response of peripheral blood mononuclear cells to glutamate decarboxylase in insulin-dependent diabetes. Lancet 339: 458-459

15. Tisch R, Yang XD, Singer SM, Liblau RS, Fugger L, McDevitt HO (1993) Immune response to glutamic acid decarboxylase correlates with insulitis in non-obese diabetic mice. Nature 366: 72-75

16. Barrett-Connor E (1985) Is insulin-dependent diabetes mellitus caused by coxsackievirus B infection? A review of the epidemiologic evidence. Rev Infect Dis 7: 207-215

17. King ML, Bidwell D, Shaikh A, Voller A, Banatvala JE (1983) Coxsackie-B-virus-specific IgM responses in children with insulin-dependent (juvenile-onset/type 1)diabetes-mellitus. Lancet 1: 1397-1399

18. Frisk G, Friman G, Tuvemo T, Fohlman J, Diderholm H (1992) Coxsackie B virus IgM in children at onset of type 1 (insulin-dependent) diabetes mellitus: evidence for IgM induction by a recent or current infection. Diabetologia $35: 249-253$

19. Atkinson MA, Bowman MA, Campbell L, Darrow BL, Kaufman DL, Maclaren NK (1994) Cellular-immunity to a determinant common to glutamate-decarboxylase and coxsackie-virus in insulin-dependent diabetes. J Clin Invest 94: 2125-2129

20. Leslie RDG, Elliot RB (1994) Early environmental events as a cause of IDDM - evidence and implications. Diabetes 43: 843-849
21. Lohmann T, Leslie R, Hawa M, Geysen M, Rodda S, Londei M (1994) Immunodominant epitopes of glutamic-acid decarboxylase-65 and decarboxylase-67 in insulin dependent diabetes mellitus. Lancet 343: 1607-1608

22. Olerup O, Zetterquist H (1993) HLA-DR typing by polymerase chain reaction amplification with sequence specific primers (PCR-SSP). In: Hui KH, Bidwell L (eds) Handbook of HLA typing techniques. CRC Press, London, pp 149-173

23. Jones DB, Armstrong NW (1995) Coxsackie virus and diabetes revisited. Nature Medicine 1: 284

24. Armstrong NW, Jones DB (1994) Epitopes of GAD65 in insulin dependent diabetes mellitus. Lancet 344: 406407

25. Dalessio DJ (1992) A case-control study of group-B coxsackievirus immunoglobulin-M antibody prevalence and HLA-DR antigens in newly diagnosed cases of insulin dependent diabetes mellitus. Am J Epidem 135: 1331-1338

26. Bruserud O, Thorsby E (1985) T lymphocyte responses to coxsackie B4 and mumps virus. Influence of HLA-DR restriction elements. Tissue Antigens 26: 41-50

27. Richter W, Mertens T, Schoel B et al. (1994) Sequence homology of the diabetes associated autoantigen glutamate decarboxylase with coxsackie B4-2C protein and heat shock protein 60 mediates no molecular mimicry of autoantibodies. J Exp Med 180: 721-726

28. Hou J, Said C, Franchi D, Dockstader P, Chatterjee NK (1994) Antibodies to glutamic acid decarboxylase and P2$\mathrm{C}$ peptides in sera from coxsackie virus B4-infected mice and IDDM patients. Diabetes 43: 1260-1266

29. Kaufman DL, Clare SM, Tian J et al. (1993) Spontaneous loss of T-cell tolerance to glutamic acid decarboxylase in murine insulin-dependent diabetes. Nature 366: 69-72

30. Tian J, Lehmann PV, Kaufman DL (1994) T-cell cross-reactivity between coxsackie virus and glutamate-decarboxylase is associated with a murine diabetes susceptibility allele. J Exp Med 180: 1979-1984

31. Wucherpfennig KW, Strominer JL (1995) Molecular mimicry in T cell-mediated autoimmunity: viral peptides activate human $\mathrm{T}$ cell clones specific for myelin basic protein. Cell 80: 69.5-70.5 